\title{
ИДЕНТИФИКАЦИЯ И ОБРАЗ АДРЕСАТА В ИНТЕРНЕТ-СОБОЛЕЗНОВАНИЯХ
}

\author{
IDENTIFICATION AND AN IMAGE OF THE RECIPIENT \\ OF INTERNET CONDOLENCE LETTERS
}

\begin{abstract}
АНДЖЕЙ НАРЛОХ
ABSTRACT. An internet condolence letter has become a new form of communication in special circumstances. The selection of appropriate vocabulary plays a vital role in writing internet condolence letters as it is indirectly connected with expressing sympathy, support and understanding. In addition, the form of addressing the recipient often determines the right reception of a condolence letter. A recipient is identified in apostrophes in many ways. His or her nationality is emphasized most frequently. Also, ethnicity and social relationships are quite often indicated. Very emotional apostrophes directed to the dead have also been found in the analyzed material. Each kind of identification requires using suitable means of expression. Many of them contain additional emotive language. The analyzed apostrophes are very emotional and full of positive evaluative expressions. All the same, there are also many official, almost pompous constructions.
\end{abstract}

Andrzej Narloch, Uniwersytet im. Adama Mickiewicza w Poznaniu, Poznań - Polska.

Соболезнование пишут в связи с конкретным событием, поэтому контекст становится фоном языкового коммуниката, в котором возникает данный жанр. Соболезнование имеет свои системный, стратегический и тактический уровни (Т.В. Анисимова, О.Н. Паршина) и может выражаться в письменной или устной форме. В настоящей статье анализируется письменная разновидность соболезнования - интернет-соболезнование, которое отличается своей композицией и специфическим языковым содержанием на фоне стереотипных для этого жанра языковых средств выражения. Анализировались свыше 800 соболезнований, помещенных на электронном периодическом издании РИАН.Ру1.

\footnotetext{
${ }^{1}$ Материал был собран после крушения польского президентского самолета 10 апреля 2010 года. После этой трагедии редакция электронного издания (сайт: www.rian.ru) предоставила возможность поместить соболезнования русских для
} 
В настоящей статье внимание сосредоточивается на проблематике идентификации адресата соболезнований. В данном жанре исключительную важность приобретает контактоустанавливающая функция, позиционирующая участников коммуниката с точки зрения социальных взаимосвязей. В связи с этим важным представляется функция и роль обращений, т.е. тех элементов, которые идентифицируют адресата коммуниката. Ведь то, как мы обращаемся к другим в трудной для них жизненной ситуации, является залогом искренности нашей позиции. Эти факторы непосредственно сказываются на стилевой и структурной специфике жанра.

Остановимся вкратце на жанре соболезнования, который следует отнести к эмотивным, так как разделение или улучшение эмоционального состояния адресата ставится во главе принципиальных функций ${ }^{2}$. По словам Ю.В. Казачковой, такие речевые жанры, как сочувствие, утешение, соболезнование, „появляются в речи как реакция на различные негативные для человека ситуации"з

Соболезнование как жанр располагает собственным набором языковых средств. В их состав входят стандартные устойчивые конструкции, связанные с выражением соболезнования, а также с элементами сочувствия и утешения, напр.: выражать соболезнование, пусть земля будет пухом, Бог даст силы пережить трагедию, разделять утрату, скорбеть вместе с семьей, потрясти до глубины души, невосполнимая потеря, страшная трагедия и др.

С точки зрения требований, идущих от самого жанра, форма анализируемых писем-соболезнований не задана очень жестко и отличается разрушением стилевой структуры. Уход от жесткой стилевой композиции, которой обычно отличается соболезнование, обусловливается рядом причин. К ним можно отнести следующие: 1) специфику канала коммуникациин; 2) идентификацию адресата; 3) стихийный (неподготовленный) характер образования соболезнований; 4) отсутствие эмо-

поляков. Следует отметить, что всего на сайте было опубликовано около 2000 соболезнований на русском и других языках.

2 М.Ю. Ф е д о с ю к, Комплексные жанры разговорной речи: „утешение”, „убеждение” и "уговоры", [в:] Русская разговорная речь как явление городской культуры, Екатеринбург 1996, с. 78.

${ }^{3}$ Ю.В. К а з а ч к о в а, Выражение сочувствия в русском и английском речевом общении. Дисс. ...канд. филол. наук, Саратов 2006, с. 6-7.

${ }^{4}$ Канал коммуникации имеет опосредованный дистанционный характер и не направлен лично к конкретному адресату. Функцию канала выполняет Интернет.

5 Соболезнования возникали стихийно, без особой подготовки, являясь душевным ответом на случившуюся трагедию и попыткой поделиться своими чувствами с другим народом. 
циональных отношений с адресатом 6 ; 5) частичная анонимность адресан$m a^{7}$.

В собранном материале употребление обращений (апеллятивов) в структуре соболезнования становится обязательным речевым актом, предопределяющим эмоционально-эмотивную сторону коммуниката, формируя целостный композиционный конструкт. Следует отметить, что некоторые ученые, в частности Д. Вундерлих, рассматривали обращение как независимый речевой акт. Д. Вундерлих определял его основную цель как привлечение и поддержание внимания адресата ${ }^{8}$. Такую функцию привлечения внимания, по определению Л.П. Рыжовой, можно назвать вокативной 9 .

Общепризнанно, что основная функция обращения состоит в том, чтобы назвать адресата речи, привлечь внимание или поддержать внимание собеседника. Однако в соболезновании обращение не ограничивается только приведенными функциями. Кроме вытекающих из грамматической природы функций, они вносят аксиологическую нагрузку, т.е. оценку адресата, субъективное отношение к адресату. Обращения раскрывают также социально-общественные взаимоотношения с собеседником (родственные, социальные, деловые и др.). Как считает Н.Д. Арутюнова, обращение с функциональной стороны имеет двойственный характер, т.е., с одной стороны, позволяет адресату идентифицировать себя как получателя речи, с другой - служит выразителем отношения говорящего ${ }^{10}$.

В.В. Голикова выделяет следующие речевые функции, выполняемые обращениями: 1) номинативную; 2) характеризующую (функцию демонстрации личного отношения к адресату); 3) этикетную (или социально-регулятивную функцию, связанную с конвенциональными нормами поведения для различных социальных ситуаций)11. Именно выражение отношения говорящего, его эмоционального состояния

${ }^{6}$ Адресант соболезнования в подавляющем большинстве лично не знаком с адресатом. Это находит свое выражение в идентификации адресата, которым часто становится абстрагированный, обобщенный адресат.

7 Идентификация адресанта осуществлялась на основании добровольного приведения имени, фамилии, города проживания и выполняемой профессии.

8 D. W u n d e r l i c h, Studien zur Sprachakttheorie, Frankfurt am Main 1976, c. 295.

9 Л.П. Р ы ж о в а, Обращение как компонент коммуникативного акта. Автореф. дис. ...канд. филол. наук, Москва 1982, с. 9.

10 Н.Д. А р у т ю н о в а, Предложение и его смысл: логико-семантические проблемы, Москва 1976, с. 355.

11 В.В. Г о л и к о в а, Функции обращения в семейном дискурсе, „Теория языка и межкультурная коммуникация. Электронный научный журнал", № 1 (5). 
становится основным в собранных соболезнованиях, что обусловливается также требованиями самого жанра.

Обращения функционируют в качестве универсального средства для обслуживания человеческого общения и установления связи между высказываниями и субъектами общения ${ }^{12}$. Они несут значительную коммуникативную нагрузку и выполняют, как отмечалось выше, ряд речевых функций в процессе квази-диалога.

С синтаксической стороны обращение может входить в состав структуры предложения или может быть выведено за интонационно-композиционные рамки предложения. В таком случае оно получает функцию самостоятельного сообщения.

А.М. Серебренников указывает на двойственность номинативной функции апеллятива, которая проявляется в совмещении идентифицирующих номинаций с элементами субъективно-оценочного характера $^{13}$. Субъективно-оценочный тип обращений проявляется в форме выражения личного отношения к адресату, что отражает характеризующую функцию апеллятивов. В проанализированном материале рядом с идентифицирующей (номинативной) ориентацией, выступает характеризующая (оценочная) функция.

В письмах-соболезнованиях адресат идентифицирован за счет:

1) национальной принадлежности,

2) этнической принадлежности,

3) регулятивных отношений,

4) самих пострадавших.

Ниже представлены отдельные типы идентификации адресата, способы их реализации, а также выполняемые ими функции.

\section{1. Идентификация по национальной принадлежности}

Данный тип идентификации выражается, с одной стороны, путем обращения непосредственно к самому государству, с другой - к нации, к народу. Этот тип идентификации адресата приобретает наиболее обобщенный и абстрагированный характер. Причину этого следует усматривать в том, что размах трагедии, постигнувшей народ, убеждает адресанта, что эту трагедию переживают все, что страдает весь народ, что все потеряли если не родного человека, то, по крайней меpe, часть своего государства. В результате наступает крайнее обобщение адресата.

Обращение непосредственно к Польше сказывается таже на стилистической стороне соболезнования, подчеркивая официальный характер коммуниката, его приподнятость и даже патетичность. Согласно

12 В.Е. Г о л ь д и н, Обращение: теоретические проблемы, Саратов 1987, с. 4-64.

13 А.М. С е р е б р е н н и к о в, Языковая номинация, Москва 1982, с. 19. 
С.А. Рылову, соболезнование, с одной стороны, относится к „разговорному стилю, с другой - к официально-деловому"14. Первый стиль требует отбора интимно-ласкательной лексики и недлинных, „доходчивых" (по С.А. Рылову) предложений-высказываний. Второй предполагает употребление книжной лексики и устойчивых конструкций. Именно второй тип преобладает в конструкциях, в которых идентификация адресата прослеживается за счет государственной характеристики.

Приведем примеры: Польша, мы скорбим вместе с тобой! (Александра, Новосибирск)15; Польша, прими наши соболезнования (Полина, Екатеринбург); Польша, мы скорбим и плачем вместе с Вами (Дарья, Ярославль); Польша, ирими мои искренние соболезнования! (Дмитрий, Санкт-Петербург); Скорблю вместе с тобой, ПОЛЬША, по всем погибшим... (Елена, Окуловка); Польша, русские люди всем сердием с вами... (Ирина, Белгород). Обращение непосредственно к государству указывает также на официальность письма-соболезнования. Тем не менее, как показывают примеры, такая официальность не лишена и эмоциональных элементов.

Иногда идентификация по государственной принадлежности реализуется в неофициальной форме, в которой имеются элементы разговорности, ср.: Мы с вами, Польша! (Женя, Москва); Польша! Нет слов ... Просто комок к горлу... (Алексей, Красноярск); Прости нас, Польша! (Сергей, Самара); Польша, держись! (Светлана, Москва).

Со структурной стороны в подавляющем большинстве обращение Польща употребляется самостоятельно без субъективно-оценочных определителей. Нами зафиксирован лишь один пример с оценочным прилагательным дорогая, при сохранении пафоса: Дорогая Польша! Мы с тобой в этом горе вчера, сегодня и всегда! (Александра, Симферополь).

Второй тип идентификации по национальной принадлежности сосредоточивается на выражении адресата через призму нации (народа). Адресант рассматривает участника коммуниката с точки зрения исторической и политической общности людей, образовавшейся в результате формирования этнических особенностей и располагающей общностью самосознания и социальной структуры. Такое позиционирование адресата носит социально-политический характер.

В качестве номинаций употребляются слова, идентифицирующие получателя с точки зрения национальности и политико-правовых от-

14 С.А. Р ы л о в, Функциональная стратификация древнерусской и старорусской речи, „Вестник ННГУ”, серия: „Филология” 2000, № 1, с. 193.

15 Автор письма-соболезнования подписывался чаще всего своим именем и фамилией, городом проживания, а также профессией. В настоящей статье мы приводим только имя и город или только имя автора (если автор не привел названия города). 
ношений. В таких письмах в функции обращения употребляются, в частности, слова: поляки, народ, граждане. Употребление подобной лексики предопределяет официальный характер обращений. Официальность подкрепляется отсутствием непосредственного контакта адресанта и адресата, а также отсутствием их личного знакомства: Дорогой народ Польщи! (Юрий, Ханты-Мансийск); Поляки, мы с вами (Вадим, Москва); Граждане Польши! Мы братья-славяне! (Максим, Владимир); Уважаемые граждане Польши! Трагедии в Катыни - наша общая боль (Людмила, Касимов).

Официальность обращений дополняется также лексическим значением остальных элементов в составе письма-соболезнования, в частности употреблением стереотипных конструкций с глаголами скорбетъ, соболезновать и др. Приведем примеры: Уважаемые поляки. Искренне соболезную Вам (Елена, Екатеринбург); Поляки! Сегодня мы с Вами скорбим о большой утрате (Андрей, Иркутск); Поляки, Тюмень скорбит вместе с вами! (Тамара, Тюмень); Самые искренние слова соболезнования всем вам, поляки! (Анна, Москва); Народ Польши, мы скорбим вместе с вами (Николай, Набережные Челны).

При этнониме поляки довольно часто употребляются различного типа характеризующие языковые знаки. Поэтому идентифицирующий компонент очень часто связан с элементом субъективно-оценочного характера, выражаемого за счет оценочных прилагательных, которые становятся обязательной частью этикета: дорогой, уважаемый, глубокоуважаемый. Ср. примеры: Дорогие поляки! Сопереживаю и сочувствую Вашему горю... (Алексей, Санкт-Петербург); Дорогие, глубокоуважаемые поляки!; Дорогие поляки! Мы с вами, мы же родные! (Татьяна, Владивосток); Дорогие поляки!!! Держитесь! (Алина, Казань); Дорогие поляки, искренне и глубоко сопереживаю вместе с вами (Валентина, Тверь); Дорогие поляки! Примите искренние соболезнования... (Алексей, Липецк); Дорогие граждане Польщи! (Антонов, Екатеринбург); Уважаемые граждане Польщи! (Людмила, Касимов); Уважаемые польские граждане! (Радик, Казань); Дорогие граждане Великой Польши! (Михаил, Уфа); Дорогие граждане независимой Польщи (Николай, Москва); Уважаемый народ Польщи! (Александр, Нижний Новгород). Именно употребление оценочных прилагательных подчеркивает положительную ориентацию контактов между адресантом и адресатом. Как показал материал, высокочастотны, в частности, конструкции с прилагательными дорогой, уважаемый.

\section{2. Идентификация по этнической принадлежности}

Данный тип идентификации адресата опирается на общий генезис двух народов, на их общие корни. Этническая общность имеет целью подчеркнуть не только общее генетическое родство, но и систе- 
му ценностей, включающую похожую славянскую ментальность с ее гостеприимностью, открытостью, сердечностью в отношениях между людьми, а также сострадание и уважение традиций. Обращения с таким идентификатором ориентированы на сближение народов. Ср. примеры: Славяне, крепитесь! (Василий); Славяне! Давайте жить дружно! (Виталий, Электросталь); [...] мы же с Вами, славяне, поляки (Вячеслав, Красноярск).

Как показал материал, чаще всего рядом со словом славяне употребляется слово братья. Эмоциональность таких апеллятивов бесспорно усиливается, ср.: Мир Вам, братья славяне. Пусть эта случайная и трагическая гибель ярких представителей польского народа не будет напрасной (Николай, Оренбург); Братья славяне... мы скорбим вместе с вами... самые искренние соболезнования... (Кирилл, Орёл). Обе лексемы образуют также композит, ср.: Скорбим вместе с вами, дорогие братья-славяне (Юлия, Санкт-Петербург); Мужайтесь, братья-славяне (Александр, Чебоксары); Это огромное горе и тяжёлое испытание для польского народа; но и для нас эта трагедия - потрясение. Держитесь, братья-славяне! (Светлана, Москва). Таким образом, данные обращения становятся важным элементом этнической идентификации коммуникантов.

\section{3. Идентификация по межличностным отношениям}

Регулятивные номинации, или обращения-регулятивы, выражают родственные, социальные, территориальные отношения между адресатом и адресантом соболезнования.

По словам Н.И. Формановской, с помощью таких обращений „выражаем свое отношение к адресату, создаем определенную тональность общения, как правило, непринужденную, дружескую, иногда фамильярную"16. Обращение-регулятив устанавливает межличностные отношения между двумя участниками. По В.В. Голиковой, это отражает равенство или неравенство, общественное положение, соотношение возраста, пола, степень знакомства, что доказывает зависимость выбора обращения от сферы общения, т.е. от официальной до фамильярной, интимной ${ }^{17}$. Непринужденный стиль не ограничивает свободу выбора языковых средств выражения и употребление фамильярной и интимной лексики с большим эмоциональным зарядом. В проанализированном материале нами выявлены следующие типы идентификации, устанавливающие социальные и локальные взаимоотношения:

${ }_{16}$ Н. И. Ф о р м а н о в с к а я, Речевое взаимодействие: коммуникация и прагматика, Москва 2007, с. 201.

17 В.В. Г о л и к о в а, Функции обращения..., указ. соч. 
- Идентификация по степени близости отношений. Настоящая группа объединяет обращения, которые передают степень близости контактов между адресатом и адресантом. В таком типе обращений очень часто употребляется слово друзья, что предопределено этикетом, а не личным знакомством между адресатом и адресантом. Приведем несколько примеров: Друзъя! Мы всей семъёй скорбим вместе с вами! (Игорь, Зеленоград); Друзья, стойкости и мужества вам в эти дни! (Юрий, Тверь); Скорбим вместе с вами, друзья! (Юрий, Москва); Держитесь, друзья! (Денис, Ульяновск); Друзья! Бесконечно скорблю вместе с вами (Ирина, Ярославль). Такие обращения осложняются также оценочными прилагательными милый, дорогой, ср.: Держитесь, милые друзья [...] (Юлия, Москва); Дорогие друзья! (Татьяна, Москва); Дорогие польские друзья! Примите искренние соболезнования в случившейся трагедии, которая потрясла весь мир (Николай, Ярославль); Мы с вами, дорогие друзья (Леонид, Йошкар-Ола). Употребление местоимений наш, мой приводит к субъективизации авторского мнения. Этот стилистический прием используется в следующих экземплификациях: Наши польские друзья, примите мои слова соболезнования (Анатолий, Щелково); Дорогие наши польские друзья! (Елена, Днепродзержинск); Поляки, друзья мои [...] у нас с вами много поводов для взаимных упреков (Евгений, Ярославль). Появляются также композиты: Друзъя-соседи! (Любовь, Жуковский). Такие конструкции создают впечатление о дружеских, приятельских отношениях между участниками коммуниката, о сопереживании и сочувствии, а также о том, что все разделяют боль и трагедию людей.

- Семейная идентификация. Данная группа охватывает апеллятивы, в которых употребляется лексика, указывающая на тип семейных отношений. Наличие таких конструкций на самом деле имеет целью подчеркнуть степень близости, сердечности между адресантом и адресатом, а не фактических семейных связей. В этой функции используются такие слова, как братья, сёстры, создающие впечатление принадлежности к определенному семейству, будто семье, и тем самым идентифицирующиеся с пережитой трагедией. Приведем примеры: Братья, искренне скорбим! (Сергей, Ухта); Братья, мы с вами! (Александр, Брест); Дорогие братья! Глядя с небес, наши предки не ищут разборок и междоусобич меж нами. Это горе на всех и будущие радости даваите делить пополам (Андрей, Оренбург); Держитесь БРАТЬЯ! (Александр, Санкт-Петербург); Дорогие польские братья (Сергей, Смоленск). Слово сёстры не употребляется самостоятельно в функции обращения, 
а лишь в составе со словом братья, ср.: Дорогие польские братья и сёстры! (Вера, Москва); Уважаемые друзья, братья и сёстры! (Сергей, Москва); Глубочайшая скорбъ и соболезнование вам, мои братья и сёстры поляки (Ирина, Днепропетровск). В функции обращения употребляется также композит-новообразование: Братья-иоляки! (Татьяна, Москва), вместо часто встречаемого устойчивого братья-славяне.

Интенсивность теплых и откровенных отношений повышается в случае, когда обращение выражено субстантивированными притяжательными местоимениями мой, наш, подчеркивающими, как отмечалось, субъективизацию суждений, ср.: Дорогие мои, поверьте, что в эти дни мы с Вами (Нина, Барнаул); Дорогие наши, так сложилось, что у нас общие корни... (Елена, Москва). Такие конструкции создают картину близких и задушевных контактов, квази-беседы, так сказать, „по душам", выполняющие одновременно терапевтическую функцию. Интимизация за счет употребления такой лексики создает атмосферу достоверности и искренности позиции адресанта, и тем самым влияет на формирование его позитивного образа, а также положительных мыслей у адресата.

- Территориальная идентификация. Настоящая группа объединяет обращения, указывающие на территориальное положение участников коммуниката. В таком случае в функции обращения употребляется слово соседи, ср.: Держитесь, соседи! (Сергей, Калининград); Не падайте духом, соседи, видимо, так было начертано Провидением (Александр, Ростов-на-Дону). Очень часто данное слово сопровождается оценочными экспрессивами типа: дорогой, милый и местоимением наш, ср.: Дорогие соседи!! (Денис, Калининград); Дорогие соседи! (Дмитрий, Москва); Дорогие соседи! (Ирина, Москва); Дорогие наши соседи, дорогие наши польские родственники! (Петр, Омск); Дорогие наши соседи, братья и сёстры! (Андрей, Москва); Поляки, милые наши соседи, в эту трагическую минуту русский народ скорбит вместе с вами (Екатерина, Владивосток); Скорбим вместе с вами, дорогие соседи, поляки! (Сергей, Москва); Дорогие наши соседи! Дорогие наши братья! (Наталья, Москва); Дорогие соседи, братья, граждане Польши (Анна); Дорогие соседи! Держитесь! (Валерия, Москва); Дорогие соседи, сочувствуем Вам самым искренним образом (Слава, Москва); Поляки: братья-славяне и просто соседи! (Павел); А еще хочется надеяться, что эта беда сплотит наши народы, хочется все распри оставить прошлому, мы с вами, соседи (Марина, Нижний Новгород); Братья, соседи (Степан, Брест); Братья и Сёстры Поляки, мы с Вами (Илья, Томск). 
Представленные отрывки позволяют утверждать, что письма-соболезнования представляют собой динамический процесс языковой деятельности и содержат элементы общения, квази-диалога внутри текста, напоминая диалогические формы речи. Диалогизация и динамика писем-соболезнований способствует нивелировке их официального характера. Поэтому так высокочастотны в материале обращения фамильярного и интимного характера.

Следует отметить, что некоторые обращения структурно осложнены и содержат в своем составе цепочку компонентов. Благодаря такому приему увеличивается неофициальность и интимность коммуниката. Такие структуры отражают градуальный характер эмоциональной стороны межличностных отношений. Ср.:

Дорогие поляки, братья! (Татьяна, Владивосток); Поляки, Польша, родственники погибших, примите мое глубокое и искреннее соболезнование (Татьяна, Торонто); Граждане Польши, Все Поляки и Все близкие тех, кто был 8 тот злополучный день авиакатастрофы, примите мои искренние соболезнования [...]; Уважаемые Друзья, дорогие Граждане Польской Республики! (Игорь, Железнодорожный).

\section{4. Обращение к покойникам}

В анализируемых материалах найден лишь один пример обращения не к страдающим по поводу смерти людей, а непосредственно к самим погибшим в этой трагедии. Факт обращения не к страдающим, а к тем, по поводу смерти которых сожалеют, свидетельствует о крайней степени эмоциональности. Основной становится экспрессивная функция, выражение собственного отношения к объекту мысли. Такие конструкции практически утратили свою первоначальную звательную функцию (псевдоапеллятивная функция), а их функция сводится к чистому выражению эмоции, без идентификации адресата, что функционально сближает их, таким образом, с междометиями. Такие фразы призваны создать ощущение сопереживания. Исключительной задачей подобных выражений является передача душевного состояния адресанта, проявления эмоций сильного возбуждения, отчаяния и т.Д. Ср.: Да упокоятся души ваши, братья и сёстры! Пусть земля будет вам пухом! (Василий, Нижневартовск).

При обращении к уже ушедшим из жизни людям создается впечатление псевдо-беседы между нашим и потусторонним миром. Такая псевдоапеллятивность носит характер художественного приема, отличаясь исключительной экспрессивностью.

В заключение подведем итоги. Бесспорно, коммуникация, реализующаяся в данной ситуации, подчиняется социокультурным нормам общения. Эти нормы устанавливают форму межличностных контак- 
тов и способы их реализации. В анализируемых соболезнованиях обращение не только называет получателя речи, но и является индикатором межличностных отношений.

В собранных материалах адресат писем представлен неодинаково. Адресанты используют различные методы позиционирования адресатов, что является отражением их своеобразного мировоззрения, системы ценностей. В подавляющем большинстве адресат обобщается до понятия народ. Для анализируемого материала характерна исключительная эмоциональность речи, употребление интимной, положительной, эмоционально маркированной лексики. Адресат абстрагируется также до уровня государства как такового, что является своеобразной персонификацией. Двум последним свойственны, кроме эмоциональности, элементы официальной речи, книжной лексики и стереотипизации языковых средств выражения.

Ролевые функции, выполняемые участниками коммуниката, выражают социальную позицию, степень знакомства и межличностных связей, что, бесспорно, подчеркивает зависимость обращения от коммуникативных целей и требований жанра.

Результатом применения тех или иных апеллятивов является выражение положительной оценки об адресате соболезнования. Таким образом, письмо-соболезнование превращается в особо ценную форму художественного текста. В ряде экземплификаций обращения выполняют псевдоапеллятивную функцию, которая отражает их условность, так как становится основным средством выражения эмоций. 
